\title{
Development of Gas Well Electromagnetic Valve for Remote Control
}

\author{
Yong Chen ${ }^{1, a^{*}}$, Shuangquan $\mathrm{Liu}^{2, \mathrm{~b}}$ and Xiaohong Bai ${ }^{2, \mathrm{c}}$ \\ ${ }^{1}$ Oil \& Gas Technology Research Institute, Changqing Oilfield Company, \\ Xi'an,Shaanxi710018,China \\ ${ }^{2}$ Low-permeability oil and gas exploration and development of National Engineering Laboratory, \\ Xi'an,Shaanxi710018,China

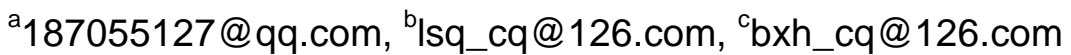

Keywords: gas field; remote control; valve

Abstract. Sulige gas field lies in the desertification area of Ordos Basin, and the natural environment is adverse there, the difficulty of using traditional methods to manage thousands of gas wells there is great. This paper introduced the development of a type of electromagnetic valve for remote control, which could open and shut in the gas wells according corresponding signals remotely. The whole structure, working principle and improvement of the key part were introduced. Meanwhile, field application was referred. The device this paper developed had advantages such as smaller appearance, energy saving and fewer trouble spots. Through wide application of the gas well electromagnetic valve for remote control, labor intensity of the field workers was reduced and automation level of the gas field was improved.

\section{Introduction}

Sulige gas field lies in the desertification area of Ordos Basin, and the natural environment is adverse there. The gas wells of Sulige gas field are scattered in a vast expanse with hardship roads between them. [1] Accordingly, the difficulty of managing thousands of gas wells there is great. On the other hand, downhole chokes are widely used in Sulige gas field for decompression and surface hydrate elimination .Once the downchoke failure occurs, the pressure of the well head will exceed the design pressure of the surface pipeline of 6.3 $\mathrm{MPa}$ and hidden danger will emerge. [2] Additionally, the surface pipelines are connected dendritically.once one of the pipeline leakage or explosion occure, under-pressure protection should function to shut up gas source, i.e., the well head. Hence, the gas well protection devices are needed.

This paper introduced the development of the gas well electromagnetic valve for remote control which could open and shut in the gas wells remotely.The whole structure, working principle and simulation are introduced.

\section{Structure Design of Gas Well Electromagnetic Valve for Remote Control}

Design Requirements According to the production environment of the gas wells in Sulige gas field, commercial power is unavailable there. Meanwhile, safety factor should be taken in to account. So,the electromagnetic valve for remote control should be designed with a characteristic of self-holding to avoid the hidden danger to the gas production brought by the long-term electrified electromagnetism coil. The actions of open the wells or cut off the pipelines should be triggered by weak current which generated by solar power. [3]

On the basis of the actual situation of the gas well, the parameters of the electromagnetic valve were determined as follows: First, the action time is shorter than 1s. Second, the rated pressure is $25 \mathrm{MPa}$. Third, the power is $30 \mathrm{~W}$ at the most.

The Whole Structrue The gas well electromagnetic valve for remote control is mainly comprised of valve cover, valve body, main valve plug, compression spring, mini electromagnetic valve etc. The concrete structure is shown as Fig.1. 

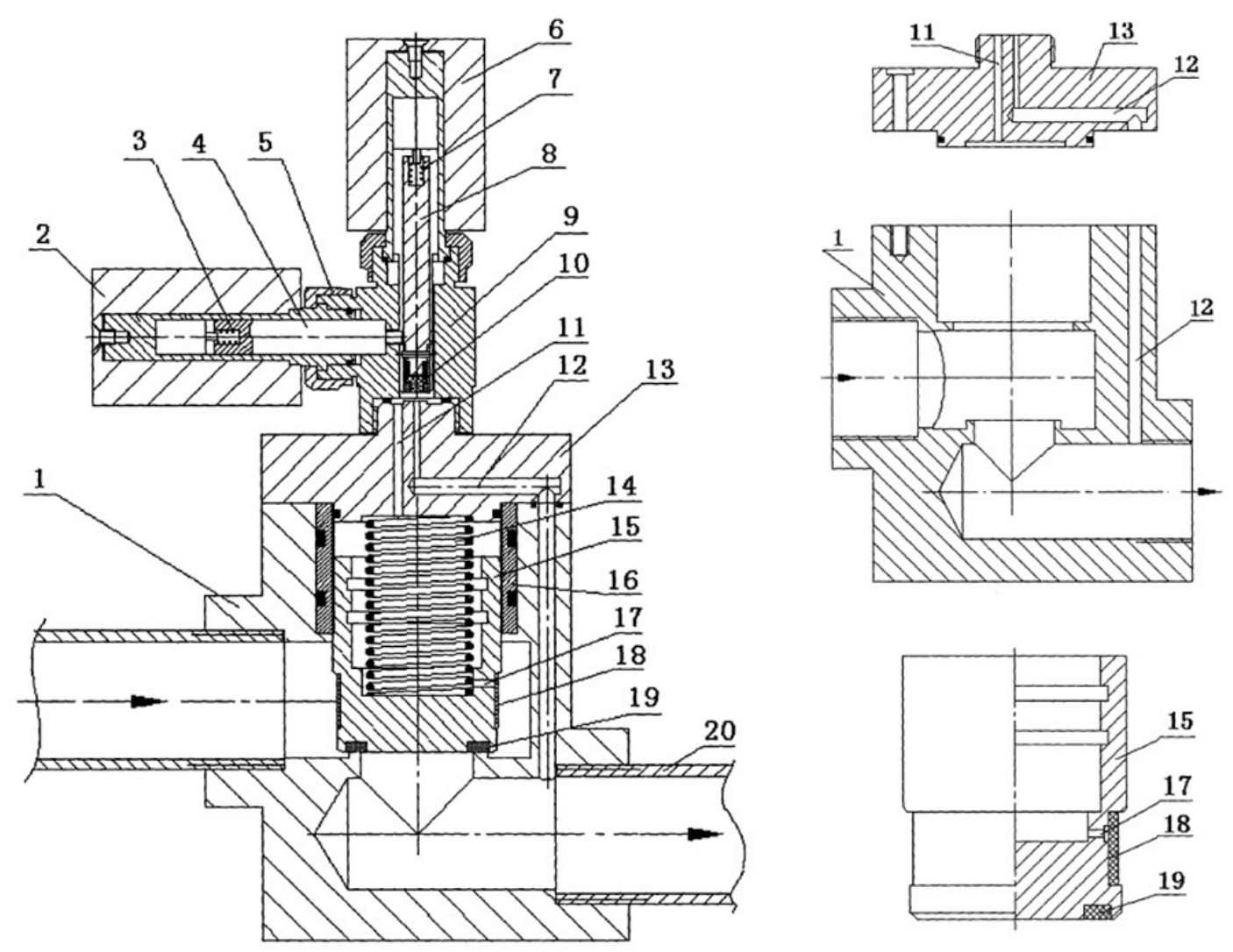

1.valve body,2. horizontal mini electromagnetic valve,3.horizontal spring,4.horizontal magnetic core, 5.union cap,6.vertical mini electromagnetic valve,7.vertical spring,8.vertical magnetic core,9. fixed seat, 10.seal cover,11. pressure relief pore canal,12. connection pore canal,13.valve cover,14. compression spring, 15.main valve plug, 16, inner lining, 17.pressure balance pore,18.sieve,19. gasket,20. downstream pipeline

Fig. 1 The concrete structure of gas well electromagnetic valve for remote control

The main valve plug is the actuating mechanism which could open or shut in the upstream and downstream gas flow passages. It could be lift by the differential pressure between top and bottom of it. The mini interlocking electromagnetic valves could open or cut off the inner gas canals according to the remote control signals to fulfill various functions. The remote control signals are emitted by the station control system via transceiver and processed by RTU(remote control unit).

Working Principle The gas well electromagnetic valve for remote control is opened or closed by opening or closing the pressure relief pore on the valve cover. As shown in figure 1.

Open-on valve principle. When the function of opening the valve was needed, vertical mini electromagnetic valve was energized and vertical magnetic core was sucked up. At same time, horizontal magnetic core of horizontal mini electromagnetic valve strech-out under the force of horizontal spring and the front end of it embed in the ring channel of vertical magnetic core. Thus, vertical magnetic core was locked and coil is power off. The connection pore canal was opened this moment and the canals from the pressure relief pore to downstream pipeline via connection pore canal were unobstructed. Correspondingly, the high pressure of inner cavity of main valve plug decrease and main valve plug was lifted by the pressure differential between the outer ring of bottom and top. So, the upstream pipeline and the downstream pipeline was connected and the valve was opened-on.

Shut off valve principle. When the function of opening the valve was needed, such as overpressure occurring, horizontal mini electromagnetic valve was energized and horizontal magnetic core was sucked up. It retract from the ring channel of vertical magnetic core. At same time, vertical magnetic core of vertical mini electromagnetic valve was unlocked and moved down under the force of vertical spring and the front end of it blocked off the connection pore canal. The coil of horizontal mini 
electromagnetic valve was power off then. Because the pressure relief pore canal was blocked, the high pressure gas of the upstream was poured into the main valve plug via pressure balance pore and the pressure differential between the bottom and top was vanished. Thus, under the force of compression spring and gravity, the main valve plug moved downward and shut off the gas flow. Subsequently, the pressure of the upstream pipeline increased continually,so did the pressure of inner cavity of main valve plug. The higher pressure of inner cavity of main valve plug was, the tighter valve closed.

\section{Improvement of the key part and Simulation Analysis}

Improvement of the key part. In in early design, the bottom of main valve plug was flat and there was a ring protruding from the valve seat. Thus, sand grains were easy to deposit there and seal problems occurred. Additionally, the valve plug could probably be jammed by sand. So, the valve seat and valve plug were improved and $\mathrm{V}$-shaped sealing surface were adopted. The picture of sand grains deposit on the valve seat in early design is shown as Fig.2. The improved design of valve seat and valve plug is shown as Fig.3.

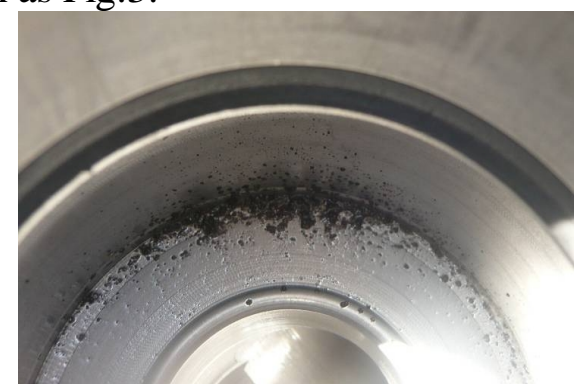

Fig. 2 The sand grains deposit on the valve seat

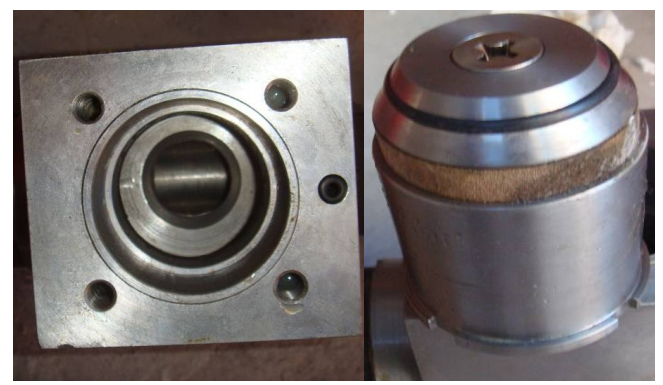

Fig.3 Improved design of valve seat and valve plug

Simulation Analysis With the help of CFD software, simulation analysis of the gas flow for sand carrying is analyzed and is shown as Fig.4. According to the analysis result, it can be seen that $\mathrm{V}$-shaped sealing surface is more beneficial to carry sand.

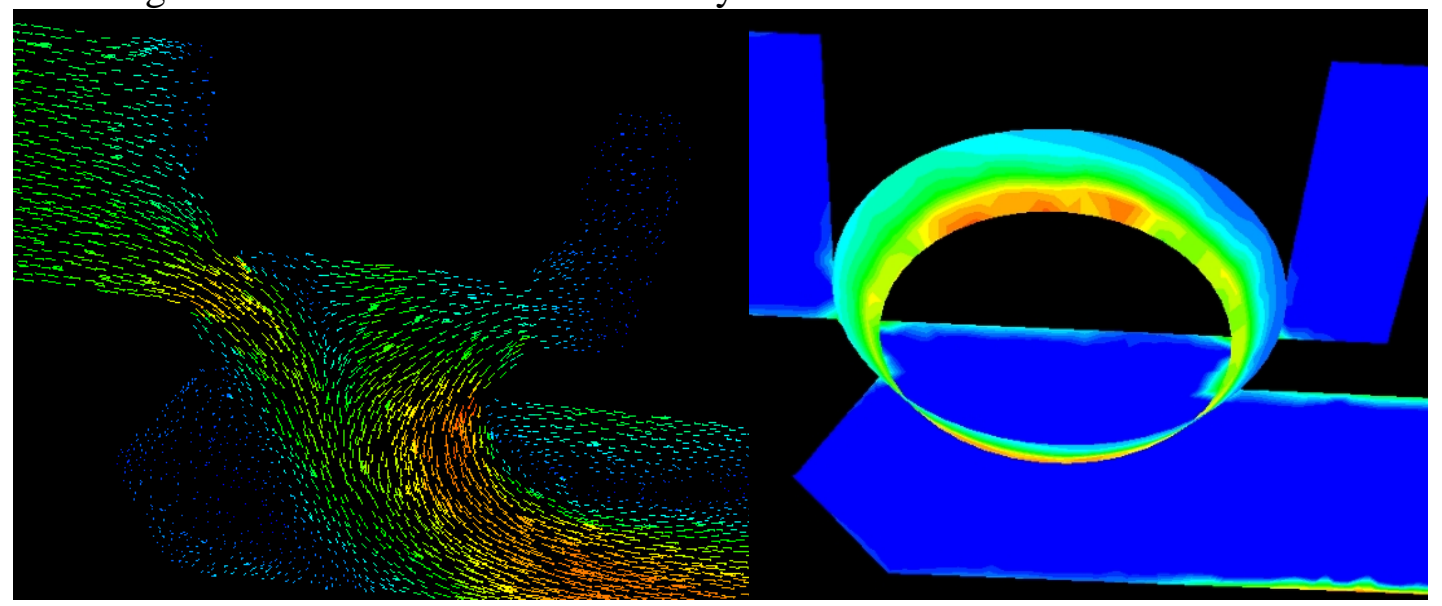

Fig.4 Simulation analysis of the gas flow for sand carrying

Field Application of the Gas Well Electromagnetic Valve for Remote Control. So far, hundreds of the gas well electromagnetic valves for remote control were applied in Sulige gas field. Field application showed that the device had a good adaptability under field conditions. The functions of protection were effective and reliable, as well as agile open-on and shut-off actions under remote control. Actual requirements of the field management were fulfilled. The picture of the well site in Sulige gas field is shown as Fig.5. The picture of gas well electromagnetic valve for remote control is shown as Fig.6. 


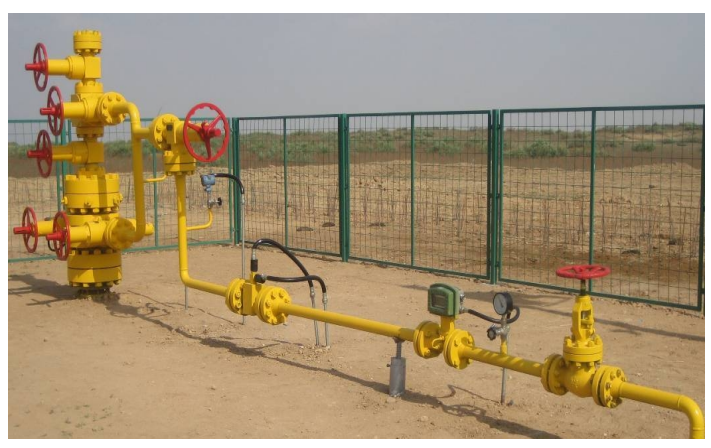

Fig.5 The well site in Sulige gas field

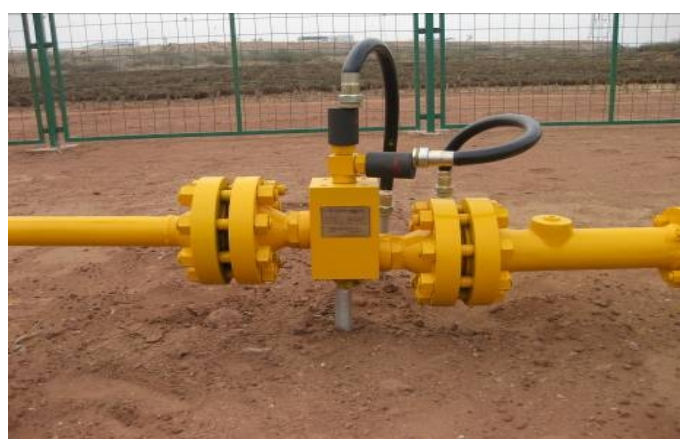

Fig.6 The gas well electromagnetic valve

Several advantages of gas well electromagnetic valve for remote control developed were shown in field application as follows: First, the device had a smaller appearance and fewer action parts. In other words, it had fewer trouble spots. Second, the action of the device rely on the gas in pipeline and no external gas souce was need.Third, the device was easy to fix and had fewer cost.

The management level of the Sulige gas field was improved through wide application of the gas well electromagnetic valve for remote control. Many field operations, such as opening and closing the gas well, could be actualized before computer now. Driving to the well site was no longer an inevitable requirement. Labor intensity of the field workers was reduced and automation level of the gas field was improved.

\section{Conclusions}

(1) The the gas well electromagnetic valves for remote control this paper developed could realize the function of opening and shutting in the gas wells remotely. The device had advantages such as smaller appearance, fewer trouble spots and energy saving. Transitorily energized and self-holding were the highlights.

(2) The device could enhance the automation level of the Sulige gas field. Safety was ensured and labor intensity of the field workers was reduced. Economic benefit and social benefit that brought by this equipment were notable.

\section{Acknowledgements}

This work is supported by the National High Technology Research and Development Program (Project code: 2011AA040401). The author appreciate the help of Senior Engineer Zhigang Yu for his support and thank all the workmates for their help with the work.

\section{References}

[1] X.Q. Ran, A.Q. Li, Sulige Gas Field Development Approach, Petroleum Industry Press, Bei Jing, 2013.

[2] Y. Chen, D. J. Chen, X. L. Cheng, Electromagnetic Valve of Remote Control for Gas Well, Oil Forum, 5(2012), 59-61.

[3] Y. Chen, X.H Bai, Y.D.Li, Development of Gas Well Opening Device for Remote Control, Advances in Engineering Research, 39(2015), 2026-2030. 